\title{
ANIMES E OTAKUS: UM OLHAR DO AUDIOVISUAL AO GRUPO
}

\author{
ANIMES AND OTAKUS: \\ A LOOK OF AUDIOVISUAL TO THE \\ GROUP
}

\section{Leandro Ayres Peres}

leandroayresperes@gmail.com

Mestre em Ciências Sociais pela Universidade Federal de Santa Maria, Especialista em Comunicação e Projetos de Mídia pelo Centro Universitário Franciscano e Graduado em Geografia e Comunicação Social pela Universidade Federal de Santa Maria.

\section{André Luis Ramos Soares}

alrsoaressan@gmail.com

Doutor em Arqueologia pela Universidade de São Paulo, Mestre em História pela Pontificia Universidade Católica do Rio Grande do Sul, Graduado em História pela Universidade Federal do Rio Grande do Sul e Presidente do Memorial da Cultura e Imigração Japonesa do RS.

\section{RESUMO}

Este artigo tem por objetivo uma análise socioantropológica sobre a veiculação de animes no Brasil e a formação do grupo otaku. Mais especificamente, ele busca evidenciar a presença dos produtos japoneses no Brasil, analisar os impactos referentes aos avanços tecnológicos na área da comunicação, averiguar as transformações na relação entre público consumidor e os produtos midiáticos e compreender como a cultura da mídia pode atuar na formação de grupos sociais. Para tal, primeiramente apresentamos um breve resumo do processo de veiculação das produções japonesas, sendo na sequência analisadas as características correlacionando a aspectos referentes ao grupo estudado.

Palavras-chave: Anime. Otaku. Sociedade.

\begin{abstract}
This article aims at a socio-anthropological analysis on the placement of animes in Brazil and the formation of the otaku group, specifically it seeks to evidence the presence of Japanese products in Brazil, analyze the impacts related to technological advances in the area of communication, find out the transformations in the relationship between the consumer public and the media products, and to understand how media culture can act in the formation of social groups. Therefore, we first present a brief summary of the process of placement of Japanese productions, being analyzed the characteristics correlated to the aspects referring to the group studied.
\end{abstract}

Keywords: Anime, Otaku, Society. 


\title{
INTRODUÇÃO
}

\author{
"Dakishimeta kokoro no kosumo \\ Atsuku moyase kiseki wo okose \\ Kizutsuita mama ja inai to \\ Chikaiatta haruka na ginga"
}

Provavelmente você não entendeu o que está escrito acima, assim como a maior parte da população brasileira não entenderia. Escrito em japonês, esse é um fragmento da canção Pegasus Fantasy, de autoria de Hiroaki Matsuzawa e interpretada pela banda japonesa Make-up. Essa música se tornou mundialmente conhecida por fazer parte da abertura da série de animação Saint Seiya, conhecida no Brasil como "Os Cavaleiros do Zodíaco". Mas o que torna ela tão importante é o fato de ter se tornado praticamente um hino para os Otakus brasileiros.

Otaku é o termo pelo qual são conhecidos os fãs da cultura pop japonesa no Brasil, Estados Unidos e em outros países. Cunhado no Japão, o termo possui, em sua origem, um significado um pouco distinto, carregado de uma carga pejorativa. Ele se refere aos fãs, aqui compreendidos segundo a perspectiva de Jenkins (2008), que será apresentada a posteriori. No caso, o termo em sua origem se referia a fãs de forma mais generalista, podendo ser fã de qualquer coisa. Muitas vezes o termo é associado a um estereótipo mais conhecido na cultura ocidental, o Nerd, devido à sua associação com as produções midiáticas que atualmente compõem uma das características que lhe é predominante e distinguindo da percepção original do termo que, de forma pejorativa, é associada a um alto grau de intelectualidade e deficientes habilidades de socialização.

Nesse contexto, a mídia aparece como algo fundamental para a compreensão tanto da formação quanto do próprio grupo Otaku. Tendo em vista o papel da mídia nesse processo, buscou-se uma aproximação teórica com o campo da comunicação almejando uma melhor compreensão do processo. Em virtude disso, este estudo foi realizado em um movimento cujo fluxo se deu do produto ao consumidor, partindo de uma análise histórica da veiculação dos animes no Brasil, sendo esta correlacionada aos avanços nas tecnologias de comunicação e analisando as características destas produções até chegar ao grupo que se forma em meio a esse complexo processo. No que cerne aos dados referentes ao grupo, eles foram compilados de uma série de inserções em campo entre os anos de 2008 e 2016.

Nessa perspectiva, é desenvolvida uma abordagem teórica ancorada na sobreposição de duas teorias base. Uma delas seria a "cultura da mídia", proposta por Kellner (2001), que considera o impacto das produções midiáticas sobre o seu público consumidor, enfatizada pelo autor através de analises de fenômenos como o das meninas que iam ao shopping vestidas como a cantora Madonna; ou o aumento de alistamentos por jovens do sexo masculino na força área estadunidense após a veiculação do filme Top Gun (1986). A outra teoria em questão diz respeito à Teoria da "Cultura da Convergência", de Jenkins (2008), a qual considera a forma como o público se apropria da mídia, em uma concepção na qual ganha destaque central o papel do fã, teoria que relaciona três fenômenos: a convergência dos meios de comunicação, o desenvolvimento de uma cultura participativa e de uma inteligência coletiva. 


\title{
ONDE A HISTÓRIA COMEÇA
}

\author{
"Quando nascemos fomos programados \\ $A$ receber o que vocês \\ Nos empurraram com os enlatados dos USA, de 9 às 6".
}

A canção "Geração Coca-Cola" da banda Legião Urbana traz em si uma perspectiva deveras importante para este estudo, o papel da veiculação massiva de produtos midiáticos estrangeiros na mídia brasileira. Apesar da crítica da música ser relativa às veiculações realizadas até a década de 1980 e servir como perspectiva de um processo de "programação" com relação aos ideais norte-americanos. A partir da década de 1990, começa a se desenvolver um processo muito mais complexo, no qual ganham destaque no Brasil as veiculações de origem japonesa.

A circulação de produtos midiáticos japoneses no Brasil teve início com o processo de migração nipônica, principalmente após a $2^{\mathrm{a}}$ Guerra Mundial, quando os mangás foram empregados pelos japoneses e seus descendentes para manter contato com sua língua materna, como destaca Sônia Luyten (2012). Desse modo, para as crianças, ele auxiliava na assimilação do que era ensinado nas escolas das comunidades, principalmente no que cerne ao complexo sistema alfabético japonês composto de três formas de escrita: Katakana, Hiragana e Kanji. Isso, além de servir como um instrumento para se manterem atualizados sobre o que acontecia no Japão.

Apenas na década de 1960 as produções japonesas chegaram às mídias de massa com produções como National Kid (1960) e Ultraman (1966), veiculadas no Brasil na segunda metade da referida década. Essas produções são conhecidas como Tokusatsus, palavra que deriva da expressão "Tokushu Kouka Satsuei", que se refere ao uso de efeitos especiais nas produções. Atualmente o termo é empregado para designar filmes ou séries de super-heróis produzidos no Japão, com bastante ênfase nos efeitos especiais.

Por duas décadas os tokusatsus foram veiculados de forma esporádica no Brasil. No entanto, essa dinâmica mudou no final da década de 1980, quando as produções desse período passaram a ser beneficiadas por uma emissora como jamais havia sido feito por algum de seus predecessores. Em um processo que teve início em 1988, a Rede Manchete de Televisão, após cinco anos de funcionamento, em um investimento arriscado com o empresário Toshihiko Egashira, passou a veicular as séries Jaspion e Changeman e que, em pouco tempo, culminou com grande parte da programação da emissora preenchida pelos heróis japoneses, fenômeno que durou até metade da década de 1990.

A exibição massiva do gênero levou ao desgaste do mesmo, o que acarretou no completo desaparecimento dessas produções na mídia tradicional brasileira no início dos anos 2000. Contudo, a exibição massiva não foi o ápice das veiculações de produções japonesas na televisão brasileira. Em meio à exibição dos tokusatsus, um novo produto conquistou o público brasileiro: o anime. Tal processo se deu de forma ainda mais peculiar, principalmente pelo papel assumido por uma obra na difusão de seu gênero, no caso o anime Saint Seiya. Contudo esse não foi um fenômeno limitado ao Brasil, Cavaleiros do Zodíaco (CDZ) aparece como algo sem precedentes, um fenômeno midiático mundial, como aponta Sato (2007, p. 44):

[...] a série em anime passou a ser exibida na Europa, Cavaleiros virou uma mania internacional provando que a mistura de mitologias tornou a história assimilável em países de culturas bastante diversas. Outro fator 
que alimentou a "febre" foi um eficiente esquema de marketing, que vinculou o desenho a anúncios de brinquedos - bonecos colecionáveis articulados com armaduras encaixáveis da fabricante japonesa Bandai, patrocinadora da série. Na França a rede TF1 exibiu e reprisou Cavaleiros por vários anos, alavancando a carreira da apresentadora e cantora pop Dorothée, âncora de um programa infantil no qual vários desenhos japoneses iam ao ar. Em 1995, no auge da popularidade, Dorothée chegou a dar shows ao vivo no qual ela entrava no palco vestindo uma armadura dourada semelhante à dos Cavaleiros. Ávidos fãs europeus consumiam tudo o quer fosse ou aparentasse que era relacionado à série - CDs, revistas, brinquedos, roupas, cards, etc. Era o toque de Midas dos Cavaleiros: tudo que tinha a imagem deles virava ouro. (SATO, 2007, p. 44).

O anime, que mescla mitologia grega com a cultura japonesa, tornou-se sucesso entre o público infantil, adolescente e juvenil. Fenômeno de audiência abrindo caminho para a veiculação de mais produções do gênero. Associado ao desenho japonês, inúmeros produtos passaram a ser comercializados no mercado brasileiro, algo que até então não era muito comum, sendo que ainda hoje alguns dess es produtos encontram-se em comercialização, como é o caso dos action figures.

Com o sucesso obtido por Saint Seiya e alguns outros animes que se popularizaram no período, ocorreu a abertura no mercado brasileiro para a circulação dos mangás. Como dito ao referenciar Luyten, a introdução destas produções no Brasil se deu com os imigrantes, mas somente a partir de 1980 houve tentativas de editoras brasileiras de comercializar mangás, contudo as tentativas não obtiveram êxito. A aceitação dos mangás a partir dos anos 2000 só se deu pelo fato de os primeiros títulos lançados serem de produções que já haviam obtido a aceitação do público através de suas versões em anime. Assim, em 2000, foram lançados mangás como "Cavaleiros do Zodíaco" e "Dragon Ball" pela Editora Conrad; e, em 2001, a Editora JBC passou a publicar os mangás "Samurai X" e "Sakura Card Captor".

Saint Seiya obteve tanto sucesso que, mesmo após o fechamento da Rede Manchete de Televisão, acabou sendo reprisado em outras emissoras. Os animes ganharam tanto destaque que passaram a fazer parte da programação de importantes canais da rede aberta de televisão, como é o caso da Rede Bandeirantes, SBT e Rede Globo. Ao longo dos anos, no entanto, essa participação foi diminuindo e, a partir dos anos de 2010, essas veiculações praticamente desapareceram da televisão brasileira. Tal fato não implicando necessariamente em uma redução do consumo dessas produções, como poderá ser visto a seguir.

\section{NOVOS CAMINHOS}

Se o consumo das produções audiovisuais provenientes do Japão até o fim da década de 1990 deu-se principalmente através da televisão, após os anos 2000 essa modalidade de consumo foi drasticamente reduzida. Animes e tokusatus já não são mais exibidos nas redes abertas de televisão. Poucas veiculações se mantiveram na primeira metade dos anos de 2010, como a série norte-americana Power Rangers, baseada no estilo tokusatsu e o anime Naruto.

Em grande parte, esse fenômeno está relacionado à redução no número de programas destinados ao público infantil, principalmente nos canais das redes abertas de televisão brasileira. Emissoras como a Rede Globo de Televisão, 
que por décadas veiculou programas como Show da Xuxa, TV Colosso e TV Globinho, atualmente não possuem nenhum programa destinado ao público infantil sendo exibido em suas grades de programação no horário da manhã.

Mesmo com a redução da veiculação dessas produções audiovisuais em suas mídias nativas, não se pode inferir uma diminuição no respectivo consumo. Pelo contrário, é possível até mesmo identificar uma intensificação no consumo de tais produções. Nesse ponto cabe observar que o período em que os animes atingiram seu ápice com CDZ, na segunda metade da década de 1990, coincide com a popularização da internet no Brasil, iniciada em 1995, quando a rede deixou de ser restrita às universidades e a grandes empresas.

Com a internet, o processo de consumo midiático sofreu profundas transformações bem como as próprias formas de sociabilidade relacionadas à mídia e aos aparatos midiáticos. Nisso, um novo grupo passou a ter papel de destaque, os Fansubs, equipes que realizam traduções de produções midiáticas como: filmes, séries, animes e mangás. Esses grupos legendam as produções, disponibilizando-as para os demais consumidores, em um processo que muitas vezes acompanha o ritmo de veiculação das obras em seus países de origem. Assim, os fãs passaram a poder acompanhar as produções estrangeiras com uma diferença de tempo mínima em relação à veiculação em seus países de origem.

No que cerne aos fansubs, eles tiveram sua origem ainda na década de 1980, quando a principal forma de distribuição das produções midiáticas eram as fitas VHS, que eram enviadas pelo correio. Com o advento da internet, a atividade cresceu, os fansubs passaram a contar com grandes equipes para traduzir e sincronizar as legendas. Um elemento peculiar em relação a estes grupos é que eles trabalham de forma gratuita, por meio de uma política de "de fã para fã", sendo que

[...] há o hábito entre os fansubs brasileiros de parar a tradução e legendagem de títulos assim que eles são licenciados no país, exatamente devido à premissa de que o trabalho deles só era realizado porque esse conteúdo não chegaria a outros fãs se não fosse por esse caminho 'alternativo'. (VIEIRA, ROCHA; FRANÇA, 2015, p. 13).

Desse modo, através dos fansubs, obras que poderiam demorar meses ou anos, ou poderiam até mesmo nem chegar ao mercado brasileiro passaram a ser disponibilizadas em baixíssimo tempo. Com os avanços nas tecnologias de comunicação, principalmente a popularização da internet de banda larga na última década, essa dinâmica acelerou-se ainda mais. Contudo, ainda hoje, a tradução e sincronização dependerão do tipo e da extensão da obra, bem como do tamanho da equipe do fansub, e se o foco dela é na qualidade ou na velocidade de publicação.

No que se refere ao tempo para veiculação de animes e mangás, o tempo mínimo médio varia de um dia a uma semana após a publicação no Japão, sendo que muitos fansubs brasileiros fazem a tradução baseada em traduções realizadas por fansubs. Como os norte-americanos, por exemplo, traduzindo, assim, do inglês para o português ao invés de traduzirem do japonês para português, dada a maior facilidade linguística para tradução.

Essa veiculação na internet através dos fansubs fez com que animes como Bleach, Fairy Tail, Naruto e One Piece se tornassem populares no Brasil mesmo antes da veiculação em redes abertas ou a cabo de televisão. E, através da ação dos fansubs, a cada dia um maior número de produções japonesas é disponibilizada, e cada vez essas produções ganham um espaço maior no consumo brasileiro, espaço esse que, se visto de perto, tende a superar as produções 
norte-americanas, que, em teoria, seriam historicamente as mais consumidas no Brasil.

Nisso, vislumbramos um ponto chave para dimensionar a abrangência da influência das produções nipônicas com relação ao público brasileiro. E, consequentemente inferir a importância da compreensão da formação de um grupo em decorrência da veiculação de produções midiáticas.

Desse modo, para dimensionar o consumo destas produções realizamos um comparativo através da ferramenta Google Trends do Google Inc., que permite analisar o volume de buscas na internet por um determinado termo. Para a análise, selecionamos quatro produções norte-americanas de grande aceitação junto ao público brasileiro e comparamos com uma das mais populares produções de origem nipônica da atualidade, Naruto. A comparação foi realizada tendo por base o território Brasileiro com o volume de pesquisas realizados entre setembro de 2012 e setembro de 2017. As informações obtidas no Google Trends foram organizadas no gráfico a seguir (Gráfico 1).

Gráfico 1 - Comparativo do volume de buscas na internet

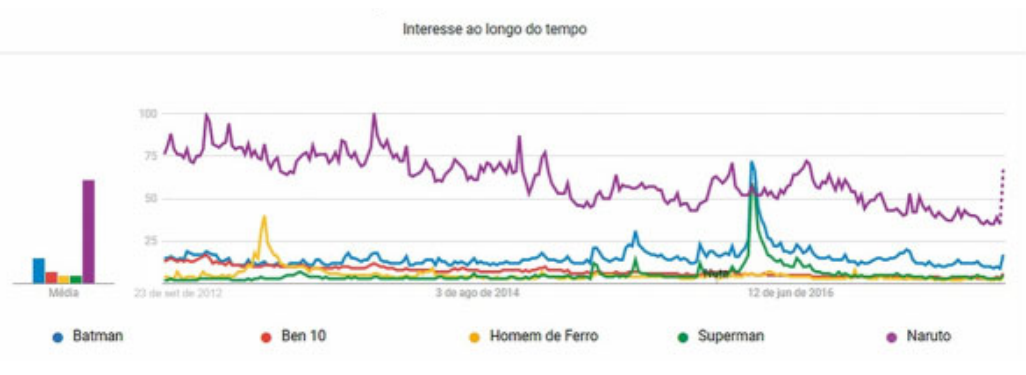

O gráfico apresenta o volume de buscas na internet pelos termos: Batman, Ben 10, Homem de Ferro, Superman e Naruto em um período de cinco anos. Conforme pode ser visto no gráfico, há uma surpreendente discrepância no volume de buscas pela produção nipônica, sendo que sua média supera os picos das demais produções em quase todo o período de análise. A única exceção se dá no primeiro semestre de 2016 devido ao lançamento da obra cinematográfica Batman vs. Superman, que resulta em um pico no volume de buscas que chega a superar o volume médio das consultas por Naruto.

No entanto também cabe considerar que o mangá de Naruto teve sua serialização finalizada em novembro de 2014, e o anime, em março de 2017, o que explica uma queda no volume de busca. Com relação a isso, cabe destacar que através da pesquisa em campo foi possível verificar que o público consumidor dessas obras tende a se manter atualizado, acompanhando e discutindo sobre o que acontecerá na série, de modo que o término das veiculações no Japão seria sucedido de uma drástica redução no volume de busca por essa obra no Brasil, já que a maior parte de seu público já a teria consumido. Ao mesmo tempo, os dados corroboram para a percepção de uma renovação desse público consumidor atribuindo às obras disponibilizadas na internet um caráter atemporal, motivo pelo qual ainda encontramos on-line obras como CDZ, Dragon Ball entre outras que fizeram parte da primeira leva de produções a conquistar o público brasileiro.

Outro elemento perceptível dentro do caso de Naruto diz respeito a como, nas mídias tradicionais, persiste a supremacia das produções norte-americanas. Nesse contexto a internet tem se desenvolvido cada vez mais como um ambiente de promoção da diversidade, sendo possível encontrar nela animes japoneses, seriados britânicos, filmes franceses, ou seja, uma infinidade de possibilidades para o consumo midiático. 
No que cerne à ação dos fansubs, a atual configuração desses grupos caracteriza o processo descrito por Anderson (2015, p. 50), no qual o "PC transformou todas as pessoas em produtores e editores, mas foi a internet que converteu todo o mundo em distribuidores". De forma que os avanços tecnológicos desde a segunda metade da década de 1990 cada vez mais favorecem ao que Anderson definiu como "democratização das ferramentas de produção", processo pelo qual o computador e a internet em especial colocam a capacidade de produção nas mãos de todos.

Assim, com a popularização da internet de banda larga após 2010, essa prática tornou-se ainda mais intensa. Os downloads deixaram de ser a única opção de acesso aos episódios disponibilizados pelos fansubs. Agora os mesmos episódios podem ser vistos on-line, através de sites dedicados a essas produções. Além disso, passaram a ser disponibilizados vídeos de melhor qualidade tanto para downloads como para consumo on-line, sendo possível o acesso a episódios em Full HD¹.

\section{DA INDÚSTRIA A CULTURA}

Com os avanços tecnológicos e, mais especificamente, pela apropriação destes por parte do público consumidor, as regras do jogo mudaram, novas perspectivas se desenvolveram para o consumo midiático. Se para a primeira geração da Escola de Frankfurt os produtos midiáticos tinham um forte papel como produtos de uma Indústria Cultural, com Kellner vislumbramos uma repaginação para a proposta de Adorno e Horkheimer. Desse modo, no lugar de uma indústria que direciona produtos com um objetivo, ter-se-ia algo mais complexo, toda uma cultura na qual o consumidor está imerso.

Tal perspectiva consolida o papel tradicionalmente atribuído à mídia de instrumento de dominação de classe, à medida que as produções nela veiculadas refletem os interesses das elites que, por sua vez, costumam ser as proprietárias dos principais meios de comunicação de massa, o que torna mais fácil perpetuar seus ideais e preservar seus interesses, influenciando o público com os conteúdos que veicula, o que leva a proposições como a de Guy Debord, da formação de uma "Sociedade do Espetáculo" e, ao desenvolvimento da teoria do agendamento midiático, através da qual "a transferência da saliência de imagens da mídia sobre o mundo às imagens de nossas cabeças. A ideia teórica central é que os elementos proeminentes na imagem da mídia tornam-se proeminentes na imagem da audiência”. (MCCOMBS, 2009, p. 111).

Perspectiva essa que nos leva ainda a inserir este processo na Teoria do Interesse, visto que o:

[...] enraizamento das ideias - sistemas culturais no terreno sólido da estrutura social, através da ênfase nas motivações daqueles que professam tais sistemas e na dependência dessas motivações em voltar-se para a posição social, mais especialmente para a classe social. Além disso, a teoria do interesse fundiu a especulação política ao combate político demonstrando que as ideias são armas, e que uma forma excelente de institucionalizar uma visão particular da realidade - a do grupo, classe ou partido de cada um - é apossar-se do poder político e reforçá-lo. (GEERTZ, 2008, p. 112).

Desse modo, se para Dumont (1997, p.13) a "introdução da ideia de estrutura é, em Antropologia Social e em Sociologia, o acontecimento capital de nosso tempo", é impreterível considerar o papel da mídia na configuração da cultura e consequentemente como agente estruturante. Isso, ainda mais à medida 
que a mídia assume cada vez mais um papel central na relação dos indivíduos entre si e com o mundo. Como aponta Simmel (2000, p. 316) à "vida é uma constante evolução, seu ritmo agitado se presencia em toda nova estrutura na qual se produz uma nova forma de ser".

Temos assim a mídia como uma estrutura que participa ativamente na modelagem e reconfiguração da sociedade, sendo que, como aponta Santaella (2003, p. 64) "quaisquer meios de comunicação ou mídias são inseparáveis das formas de socialização e cultura que são capazes de criar, de modo que o advento de cada novo meio de comunicação traz consigo um ciclo cultural que lhe é próprio".

Nesta perspectiva, consideramos que "sociedade e cultura são terrenos de disputa e que as produções culturais nascem e produzem efeitos em determinados contextos" (KELLNER, 2001, p. 13), em um processo no qual a "mídia constrói e apresenta ao público um pseudoambiente que significativamente condiciona como o público vê o mundo. (MCCOMBS, 2009, p. 47). Elemento que nos leva a considerar o diagnóstico crítico proposto por Kellner (2001, p. 15) segundo o qual:

[...] para diagnosticar as inclinações e tendências sociais, lendo em suas entrelinhas as fantasias, os temores, as esperanças e os desejos que ela articula. Um diagnóstico crítico também analisa o modo como a cultura da mídia provê recursos para a formação de identidades e promove políticas reacionárias ou progressistas - ou então põe à disposição textos e efeitos ambíguos, que podem ser utilizados de várias maneiras.

Desta forma, a Cultura da Mídia, se estabelece como:

[...] uma forma de cultura comercial, e seus produtos, mercadorias que tentam atrair o lucro privado produzido por empresas gigantescas que estão interessadas na acumulação de capital. A cultura da mídia almeja grande audiência; por isso, deve ser eco de assuntos atuais, sendo extremamente tópica e apresenta dados hieroglíficos da vida social contemporânea. (KELLNER, 2001, p. 9).

Deve-se atentar que esta é uma cultura intrinsicamente ligada aos sentidos, explorando principalmente a visão e a audição. Valendo-se dos meios de comunicação, em especial os meios audiovisuais, ela consegue atingir os consumidores para além da sua racionalidade, alcançando suas emoções, seus sentimentos. Cabe ainda ressaltar que:

[...] as diversas formas de cultura veiculada pela mídia induzem indivíduos a identificar-se com as ideologias, as posições e representações sociais e políticas dominantes. Em geral não é um sistema de doutrinação ideológica rígida que induz à concordância com as sociedades capitalistas existentes, mas sim os prazeres propiciados pela mídia e pelo consumo. $\mathrm{O}$ entretenimento oferecido por esses meios frequentemente é agradabilíssimo e utiliza instrumentos visuais e auditivos, usando o espetáculo para seduzir o público e levá-lo a identificar-se com certas opiniões, atitudes, sentimentos e disposições. (KELLNER, 2001, p. 11).

Sob esta ótica devemos considerar a proposição de Giddens, à qual

[...] as propriedades estruturais dos sistemas sociais são, ao mesmo tempo, meio e fim das práticas que elas recursivamente organizam. A estrutura não é "externa" aos indivíduos: enquanto traços mnêmicos e exemplificada em práticas sociais, é, num certo sentido, mais "interna" do que externa as suas atividades, num sentido durkeimiano. A estrutura 
não deve ser equiparada a restrição, mas é sempre, simultaneamente, restritiva e facilitadora. (GIDDENS, 2009, p. 30).

Desse modo, a mídia não impõe restrições externas, mas atua de forma interna, assimilada, como modelos de vida que atuariam como facilitadores a uma maior aceitação social. Com relação a isso, ao se considerar a Cultura da Mídia de Kellner, primeiramente deve-se considerar o período ao qual as obras por ele analisadas pertencem, no caso as décadas de 1980 e 1990, período em que a internet ainda não era tão difundida e a televisão reinava soberana no cotidiano das pessoas. Cenário também de ascensão musical relacionada à produção de videoclipes e em especial à atuação da rede de televisão MTV e sua programação composta por essas produções audiovisuais que conquistaram grande aceitação do público juvenil da época.

Tendo isso em vista, a televisão enquanto mídia predominante tinha sua programação voltada para a estrutura familiar da época, ou seja, não apenas seus conteúdos estavam voltados para a manutenção desta estrutura, como a própria grade da programação era disposta de forma a corroborar o padrão socialmente instituído.

Desse modo, programas jornalísticos e esportivos eram veiculados nos horários em que o pai provedor da família estaria em casa; programas infantis pelo turno da manhã; e programas de variedades, filmes e novelas nos demais horários, para entreter crianças e as donas de casa quando estas últimas não estivessem envolvidas com a manutenção do lar. Com isso, percebemos que, como Kellner salienta em sua teoria, mais do que um produto cultural, há toda uma cultura sobre a qual se desenvolve o consumo dos produtos midiáticos. Contudo essa perspectiva ainda preserva uma lacuna no que se trata do poder do consumidor. Muito disso devido a tal poder só ter se instaurado significativamente nas décadas seguintes ao período em análise na obra do referido autor.

Para a lacuna em questão, encontramos a resposta na teoria da Cultura da Convergência de Jenkins (2008). Apesar da temática similar, a diferença não está apenas no destaque dado à questão tecnológica, em uma perspectiva na qual as "velhas e as novas mídias colidem", mas no ponto em que tal perspectiva destaca o crescente poder do consumidor, sendo um lugar no qual "onde o poder do produtor de mídia e o poder do consumidor interagem de maneiras imprevisíveis". (JENKINS, 2008, p. 27).

De certo modo, parece ser um tanto quanto tendencioso pender para uma ou outra teoria. Se por um lado o Diagnóstico Crítico empregado por Kellner permite compreender como se estabelece uma cultura comercial baseada nos produtos midiáticos, ela tende a considerar a possibilidade da ação da mídia sobre o consumidor, mas não considera a capacidade desse consumidor propriamente dita. Por outro lado, a cultura da convergência de Jenkins foca fortemente no consumidor, propiciando lacunas no que diz respeito ao poder dos grandes detentores de capital, sendo que o poder dessa cultura não vem de:

[...] destruir a cultura comercial, mas de reescrevê-la, modificá-la, corrigi-la, expandi-la, adicionando maior diversidade de pontos de vista, e então circulando-a novamente, de volta às mídias comerciais.

Interpretada nestes termos, a participação torna-se um importante direito político. [...] O surgimento de novas tecnologias sustenta um impulso democrático para permitir que mais pessoas criem e circulem mídia. Às vezes a mídia é planejada para responder aos conteúdos dos meios de massa - positiva ou negativamente - e às vezes a criatividade alternativa chega a lugares que ninguém na indústria da mídia poderia imaginar. (JENKINS, 200, p. 326). 
Assim sendo, esta análise histórica que procuramos desenvolver, associando a veiculação de produtos midiáticos e a evolução das tecnologias de comunicação, permite-nos uma compreensão mais ampla das distinções do papel da mídia enquanto agente estruturante e seu potencial enquanto ferramenta libertária, seguindo aqui as percepções de Jenkins e Anderson, nas quais a internet propiciou um ambiente passível de ação ao cidadão comum, fazendo com que este deixasse de ser um mero receptor.

Assim sendo, é necessário considerar Cultura da Mídia e Cultura da Convergência Midiática como duas forças que variam suas posições de poder de acordo com o contexto nos quais se encontram. Se por um lado o grande capital possui uma maior capacidade de investir em mídia, por outro lado a ação de inúmeros indivíduos e a formação de grupos, como os fansubs apresentados anteriormente, não pode ser desconsiderada.

A própria perspectiva dos fansubs, por exemplo, abre espaço para o questionamento de que se não fora a atuação deles que ocasionou o término das veiculações de animes na rede aberta de televisão brasileira? Certamente tal pensamento pode parecer muito simplista, sendo as mudanças nas grades de programação das emissoras de televisão referentes às próprias mudanças sofridas pelo público consumidor ao longo do tempo. Contudo é inegável o poder que os fãs possuem hoje em dia, sendo que estes são:

[...] os primeiros a se adaptar às novas tecnologias de mídia; a fascinação pelos universos ficcionais muitas vezes inspira novas formas de produção cultural, de figurinos e fanzines e, hoje, cinema digital. Os fãs são o segmento mais ativo do público das mídias, aquele que se recusa a simplesmente aceitar o que recebe, insistindo no direito de se tornar um participante pleno. (JENKINS, 2008, p. 181).

Premissa esta visível na fala de Élcio Sodré, renomado dublador, em um evento de fãs organizado na cidade de Santa Maria-RS:

Quando eu comecei a dublar era a época dos tokusatsus, [...] depois dos tokusatsus, surgiram os animes, foi ai então que os dubladores nasceram, surgiram né, porque até então eles não existiam né, era uma coisa que ninguém sabia de onde vinha aquela voz. Com a chegada dos animes, Cavaleiros, não sei se vocês já ouviram falar (risos do público).

Ahh então vocês já ouviram falar né... (Risos do público).

Ahh é um animezinho que tem por ai né, meia-boca... (Risos do público)

Ai ele trouxe junto uma coisa que é, é da cultura oriental né, no Japão eles cultuam muito os dubladores, as vozes e tal, então aquilo foi uma surpresa pra gente que dublava. Eu tava começando ainda, tinha pouco tempo de carreira, mas tinha, tinham colegas com 15 anos já dublando e ninguém sabia quem eram. [...]

Ahnnn aí com a chegada dos animes, começaram a aparecer os otakus, começaram a aparecer as revistas especializadas né, a Herói, acho que era a Herói, tinha a Animax, todas essas revistas começaram a aparecer, e ai os otakus começaram a surgir, brotando do chão, foram se organizando né, e foi muito legal porque dai eles começaram a se interessar pelo trabalho da gente, e a gente viu que a gente existia né, poxa vida, alguém quer saber quem sou eu e tal... 
Um dos pontos mais interessantes da apresentação de Sodré foi quando o mesmo salientou que após CDZ aquele era o $95^{\circ}$ evento do qual ele participara, sendo que antes, como o próprio dublador enfatizou, "dubladores não existiam". Se por um lado o poder está centrado no grande capital, por outro lado a emergência das novas mídias gerou mais espaço para a participação dos consumidores. Em meio a isso constatamos que:

[...] as qualidades constitutivas dos atores sociais; a racionalização dessas qualidades em formas de atuação; as características não explicadas dos conjuntos de interação que provocam e permitem o exercício de tais capacidades, que podem ser analisadas em termos de elementos de motivação, e o que eu chamarei de 'dualidade da estrutura'. (GIDDENS, 1978, p. 109, grifo do autor).

Com base nesse conceito, não há estruturas independentes da ação, assim como não há agentes que cuja configuração seja alheia à estrutura. $\mathrm{Ou}$ seja, a mídia enquanto agente da estrutura não implica uma imposição, e sim uma indução, sendo pelas capacidades humanas reconfigurada, reestruturada. As estruturas estão em constante modificação, sendo que todo "indivíduo de uma sociedade, cada qual em seu próprio interesse, empenha-se em explorar a situação à medida que a percebe e, ao fazê-lo, a coletividade de indivíduos altera a estrutura da própria sociedade". (LEACH, 1996, p. 5). Se a estrutura atua sobre os indivíduos ordenando condutas sociais, os indivíduos em contrapartida, não são desprovidos de poder para alterar estas estruturas.

Desse modo, para compreender a complexidade da cultura que se forma, a Cultura da Mídia deve ser interpelada frente à convergência. As duas culturas assim resultando em uma cultura mais complexa, não definida e mutável, ou o mais correto seja dizer que culminam na proliferação de uma variedade de culturas midiatizadas, centradas no jogo de forças entre as duas instâncias, produtor e consumidor. Sendo que, como dito anteriormente ao referenciar Anderson (2009), a evolução nas tecnologias pôs a capacidade produtiva nas mãos de todos.

\title{
A GENTE SE VÊ POR AQUI
}

\author{
O que faremos a seguir? \\ Ficaremos mais fortes! \\ Vamos levantar e lutar! \\ Porque nós não estamos sozinhos! \\ (Natsu Dragneel - Personagem de Fairy Tail)
}

"Nós", a ideia de grupo presente no trecho acima extraído do anime Fairy Tail representa um recurso constantemente empregado nas produções japonesas de modo a atrair a simpatia do público, o conceito de fazer parte de algo. Esse é um dentre muitos recursos dos quais essas produções se valem para cativar o público e manter a audiência. Vejamos alguns destes recursos e no que se diferenciam das produções ocidentais de modo a levar à grande aceitação das produções japonesas.

Nessa perspectiva, o primeiro elemento a que temos que nos atentar diz respeito ao modo de produção dos animes, geralmente eles são adaptações de mangás, as histórias em quadrinhos japonesas, para o formato televisivo. No Japão o mangaká, profissional que escreve e ilustra os mangás, precisa conseguir um editor, realizar reuniões e submeter vários "names" que concorreram com os de outros mangakás por uma oportunidade de serialização. No entanto 
a serialização não é o final da jornada. Após conseguir ser serializado, o mangá que é publicado semanalmente terá que manter bons resultados. Caso sua aceitação junto ao público diminua, ele pode ser cancelado e substituído por outro.

Nesse processo, semana a semana os profissionais são obrigados a utilizar em suas obras recursos que mantenham a atratividade para o leitor, o que fez com as obras progredissem muito nesse quesito. Quando um mangá possui uma boa aceitação por parte do público, ele está sujeito a receber uma proposta de um estúdio, e os recursos empregados no enredo são automaticamente incorporados à nova mídia; bem como o fã, enquanto consumidor, passa a consumir o produto novamente no novo formato midiático em busca de uma experiência de consumo mais rica o que dá origem à inteligência coletiva trabalhada por Jenkins em sua obra: o conhecimento do universo ficcional que não está em um lugar, mas sim no ideário construído através de um imaginário coletivo.

No que cerne aos recursos empregados no enredo para manter a atenção no leitor, podemos identificar um ponto em comum, o fato de permitirem o estabelecimento do processo de identificação por parte do consumidor. Aqui concebemos que a identificação enquanto relação de:

[...] simpatia por um personagem é um efeito, e não a causa da identificação. De modo mais global, o espectador identifica-se com a situação ficcional que o filme lhe propõe pelo viés da decupagem, por exemplo, pela multiplicidade dos pontos de vista. [...] Essa primeira identificação está, portanto, 'presa à própria imagem'; o espectador identifica-se 'menos com o representado, o próprio espetáculo, e mais com aquilo que o espetáculo põe em jogo ou em cena, com o que não é visível, mas faz ver'. (AUMONT E MARIE, 2003, p.156 - Grifo do autor).

Junto a identificação, outro fator importante, colaborando para a aceitação dessas obras é a continuidade. Tanto animes quanto mangás costumam apresentar histórias contínuas ao longo de diversas publicações, sendo que muitas vezes o próprio evento de um capítulo ou episódio pode ser finalizado na edição seguinte. E isso acaba mantendo o público vinculado à obra, mesmo que de forma inconsciente, enquanto aguarda o término de um evento na mesma obra. De modo semelhante, quanto maior o número de capítulos lidos, episódios assistidos, a um maior número de elementos identificatórios estarão sujeitos os consumidores, e maior será sua imersão no universo ficcional da obra. Características que levam à percepção de que não são os traços diferenciados a principal característica destas produções, mas sim a forma como seu enredo é construído e apresentado.

Outro fator importante a ser considerado sobre animes e mangás é que sua produção é extremamente segmentada. Existem obras dedicadas para diferentes gêneros e faixas etárias. A complexidade temática vai variar de acordo com a categoria em que essas obras se enquadram, bem como o grau de sexualidade e violência presentes. Assim, tais critérios temáticos, de acordo com o gênero e faixa etária, seriam organizados da seguinte forma:

- Kodomo - público infantil;

- Shojo - para público jovem do sexo feminino;

- Shonen - para público jovem do sexo masculino;

- Josei-para mulheres;

- Seinen - para homens;

- Gekija - para público mais amadurecido. 
No que cerne ao conteúdo, as obras podem ser subdivididas ainda em tipos como:

- Magical girl (mahô shôjo ou mahou shoujo) - obras com a temática foca em garotas com poderes mágicos, como Sailor Moon eSakura Card Captor;

- Yaoi e Yuri-Obras cujo cerne é o relacionamento romântico entre personagens do mesmo sexo, como Aqua Comics, Boys L e Maria-sama ga Miteru;

- Mecha-Obras caracterizadas pela presença de robôs gigantes no enredo, como Gundan e Evangelion;

- Harém - Obras nas quais o personagem principal é rodeado de personagens do sexo oposto, comumente empregando situações cômicas nos enredos, como Ouran Koukou Host Club e Kami nomi zo Shiru Sekai;

- Ecchi - Obras que contém conteúdo sexual moderado, como: Elfen Lied e Love Hina.

- Hentai (Poruno ou Ero) - obras que possuem conteúdo pornográfico,como: Maki-Chan to Naue Tropical Kiss. (Este segmento engloba subcategorias como Shotacon, Lolicon, etc.)

Apesar da diversidade apresentada aqui, ela não é representativa da diversidade temática destas obras. Existem histórias de artes marciais, magia, esportes, tecnologia, que falam sobre realidade virtual, novos mundos, mundos alternativos, futuros apocalípticos e enredos que tratam até mesmo da própria produção de animes e mangás, que fundem magia e tecnologia, dentre inúmeras outras possibilidades. Desse modo, a grande variedade de alternativas temáticas propicia que uma dentre as diversas possibilidades disponíveis atraia o consumidor e o introduza nesse universo, em um movimento que pode vir a torná-lo um otaku ou apenas mais um consumidor, sem adentrar esse universo de forma tão aprofundada.

Nisso, um ponto a se considerar acerca destas produções é que, apesar da diversidade e complexidade variada das histórias, geralmente elas apresentam algumas características em comum, como o emprego de múltiplos personagens em foco. Ou seja, além do protagonista, existem diversos outros personagens que ganham destaque no enredo propiciando uma maior possibilidade do consumidor se identificar com um dos personagens em questão.

Muitas vezes personagens secundários disputam de tal forma a preferência com protagonistas que existem casos em que eles o superam em termos de preferência por parte do público. A exemplo disto temos os personagens de Cavaleiros do Zodíaco, ao qual o protagonista fica em quarta colocação na aceitação do público, quando comparado aos outros quatro personagens principais da obra, como pode ser visto no gráfico a seguir. 
Gráfico 2 - Personagens Preferidos do Público

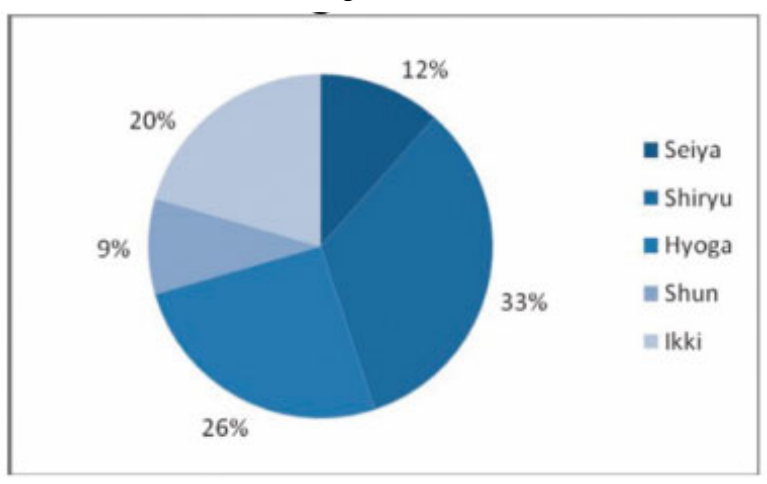

Fonte: Peres, 2008.

Contudo isso não quer dizer que a preferência do público se dê apenas entre esses personagens, como se fossem cinco protagonistas. Ao ampliar o leque de possibilidades na pesquisa, permitindo o púbico manifestar sua preferência, o número de personagens citados aumentou para trinta e oito. Nisso, os entrevistados incluíram personagens de diferentes ordens, constando até mesmo vilões. Nessa configuração, a preferência do público ficou distribuída conforme o Gráfico 3, a seguir.

Gráfico 3 - Percentual de Preferência por parte do Público

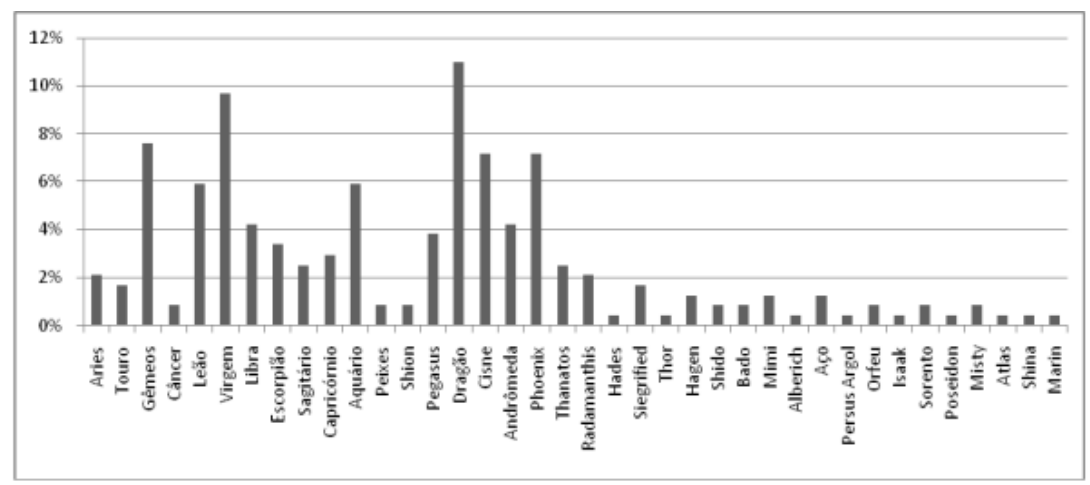

Fonte: Peres, 2011.

A partir dessa preferência dispersa entre os personagens, podemos constatar que a complexidade com que são trabalhados nas obras nipônicas criam um diferencial a partir do qual os personagens se tornam produtos mais ricos para o consumo. Em suma, há muitas possibilidades para identificação, o que propicia à grande aceitação destas obras devido à possibilidade de atingir uma variedade de público maior.

Se por um lado, como salienta Lipovetsky (2008, p.221), "o estrondoso sucesso alcançado pelas diversas manifestações da cultura midiática deva ser atribuído à sua capacidade de oferecer um universo de mudança de ares, de lazer, de esquecimento, de sonho", sendo que o que seduz o público "provém da suspensão das leis do real e do racional, da retirada da seriedade da vida, do festival de artifícios" (LIPOVETSKY, 2008, p. 188). Por outro lado, como aponta Eco (1993) ao analisar o mito do Superman, o personagem estaria fadado ao fracasso se não fosse por seu alter ego, Clark Kent. Para o autor, Clark seria um artifício de humanidade com o qual o leitor poderia se identificar, sem ele seria impossível a imersão do leitor e consequentemente o consumo da história.

Na referida análise Eco (1993, p. 248-249) destaca: 
[...] Clark Kent personaliza, de modo bastante típico, o leitor médio torturado por complexos e desprezado pelos seus semelhantes; através de um óbvio processo de identificação, um accountant qualquer de uma cidade norte-americana qualquer, nutre secretamente a esperança de que um dia, das vestes da sua atual personalidade, possa florir um super-homem capaz de resgatar anos de mediocridade.

Desse modo, as imperfeições humanas acabam sendo o ponto de entrada para a identificação. É em tal relação, entre imperfeições e as qualidades atribuídas ao personagem, que se dá a característica exposta por Lipovetsky em sua abordagem sobre a cultura mass-midiática, de que as produções midiáticas:

[...] têm o poder de fazer esquecer o real, de entreabrir o campo ilimitado das projeções e identificações. Consumimos em espetáculo aquilo que a vida real nos recusa: sexo porque estamos frustrados, aventura porque nada de palpitante agita nossas existências no dia-a-dia. (LIPOVETSKY,1989, p. 221).

Fator ainda mais evidente nas produções nipônicas, onde encontram-se personagens com características psicológicas marcantes, traumas de juventude e problemas com os quais qualquer adolescente poderia se identificar. Nessas obras é possível ver em meio ao ficcional os problemas e dificuldades encontrados pelo público bem como as qualidades intencionadas por eles. São comuns estruturas de relacionamentos entre personagens como a encontrada na obra Naruto, na qual o personagem principal que dá nome ao anime gosta da personagem Sakura, que gosta do personagem Sasuke, que não gosta de ninguém.

Situações como a citada acima, entre muitas outras que refletem a circunstâncias de constrangimento, são facilmente identificadas. Não é incomum ver uma cena em que uma personagem aparece "envergonhada", sendo esse estado destacado através da variação da tonalidade das cores no rosto da mesma, aparecendo um tom mais avermelhado. Na mesma obra, a personagem Hinata gosta do personagem Naruto, mas, por timidez, percorre quase toda a história para conseguir manifestar seu interesse. É nessas circunstâncias que animes como Naruto atingem principalmente o público juvenil, através da representação de situações em que ele se reconheça.

O público se identifica com a personagem, simpatiza com suas dificuldades e passa a torcer pelo seu sucesso. Ele passa a vivenciar a vida da personagem, acompanhando-a em sua jornada. Nisso, ele consegue satisfazer seus anseios e desejos através dessa "experiência midiatizada", principalmente de ordem emocional, obtendo elementos que lhe faltam na vida real.

Nesse processo temos a imersão do público no universo ficcional. A imersão segundo Jenkins $(2008$, p.389) diz respeito à forte identificação fantasiosa ou vínculo emocional com um ambiente ficcional, muitas vezes definida como "escapismo" ou "sensação de estar lá", o que aqui definimos como "experiências midiatizadas". Assim, concebemos as experiências midiatizadas como sendo as experiências decorrentes do consumo midiático, intrinsicamente ligadas às sensações experimentadas durante o consumo. Ao imergir em uma obra, o consumidor torcerá pelas personagens com os quais se identifica, sofrerá com seus momentos de crise, ficará feliz com suas conquistas, vivenciará através da mídia experiências distintas das reais, sobre as quais não possui controle, mas deixa-se levar durante sua busca por entretenimento.

Por esse motivo, a identificação tornou-se um conceito de fundamental importância, sendo comumente empregado na teoria do cinema, por explicar "a forte ativação de desejos inconscientes relativamente a pessoas ou a imagens, fazendo com que seja possível nos vermos na imagem ou na personagem apre- 
sentada na tela" (SILVA, 2005, p.18). Isso principalmente associado ao prazer oriundo do consumo.

No que se refere à questão ideológica, nos animes e mangás a pluralidade de temáticas e os diferentes enfoques dados não chegam a abrir uma discussão sobre um projeto de dominação ideológica, como é o caso de muitas obras norte-americanas. De modo geral, as obras tendem a trabalhar temáticas mais subjetivas, focando em ideias como superação e amizade, a luta conjunta por um objetivo, sobretudo proteger aqueles que são importantes, como fica saliente no diálogo entre os personagens Natsu Dragneel e Arlock de Fairy Tail:

"ND: amigos são companheiros que trabalham junto com você em prol de um objetivo comum!

ND: Não, eles ficam ao seu lado mesmo que os seus objetivos sejam diferentes!

ND: Amigos riem juntos e se ajudam...

ND: Eles acreditam uns nos outros.

A: Isso não é nada além de dependência.

ND: Chame da forma que quiser... Mas o que importa é que foram esses laços que me fizeram seguir em frente nos momentos difíceis.

ND: E para proteger meus preciosos amigos...

ND: Para não perder ninguém mais na minha frente...

ND: Eu vou continuar ficando mais forte!"

(Mangá Fairy Tail - Capítulo 434, páginas 12-13)

\section{VAMOS NOS DIVERTIR}

De modo geral, a identificação com as produções nipônicas desenvolve-se correlata ao divertimento no próprio consumo midiático, ao imergir na obra e viver experiências midiatizadas através dos personagens. Contudo esse divertimento não se limita ao consumo do produto midiático. Nas inúmeras incursões em campo, foi possível constatar que a paixão com a qual o público fala de seu objeto de interesse é uma constante, mas não limitada a uma esfera individual de consumo. O que se vê é um consumo compartilhado, no qual tudo que é requisitado em troca é o desejo de participar dessa troca. $O$ foco de suas ações parece convergir para um único objetivo, o de se divertir compartilhando as experiências que obtiveram através da mídia.

Essa busca de interação se manifesta em inúmeras vertentes, tirando o fã do simples ato de consumir e derivando novas possibilidades, aspecto que destaca claramente o desenvolvimento de uma cultura da participação, sendo que, como aponta Jenkins (2008, p. 30-31), ela:

[...] contrasta com noções mais antigas sobre a passividade dos espectadores dos meios de comunicação. Em vez de falar sobre produtores e consumidores de mídia como ocupantes de papéis separados, podemos agora considerá-los como participantes interagindo de acordo com um novo conjunto de regras, que nenhum de nós entende por completo.

Essa forma de cultura se desenvolveu muito devido aos avanços tecnológicos, não apenas no que tange ao acesso a uma maior quantidade de conteúdo, mas também a um maior número de possibilidades oriundas do contato com outros fãs. É nesse contexto que flui mais evidentemente o desenvolvimento da 
economia afetiva proposta por Jenkins, que parte do princípio de uma ligação emocional entre os consumidores e as produções midiáticas. Tal característica sendo explorada pelos meios de produção que não querem que o "consumidor faça uma única compra, mas que estabeleça uma relação de longo prazo. (JENKINS, 2008, p. 98).

Assim como salienta o autor há uma:

[..] nova configuração da teoria de marketing, ainda incipiente, mas que vem ganhando terreno dentro da indústria das mídias, que procura entender os fundamentos emocionais da tomada de decisão do consumidor como uma força motriz por trás das decisões de audiência e de compra. (JENKINS, 2008, p. 97).

Tal fenômeno fortemente marcado nas produções japonesas, como destacado ao apresentar o processo produtivo dos mangás (vide página 13), através do uso de recursos com os quais os fãs são levados a ver cada vez mais:

[...] programas que refletem seus gostos e interesses; os programas estão sendo planejados para maximizar elementos que exercem atração sobre os fãs; e esses programas tendem a permanecer por mais tempo no ar, pois, em casos extremos, têm mais chance de serem renovados. (JENKINS, 2008, p. 98).

Do mesmo modo, podemos vislumbrar isso ao analisarmos a própria inserção dos animes no mercado brasileiro (vide página 4). Tais produções feitas focando na experiência do consumidor, derivando a partir de um item uma série de outros produtos que tornaram essa experiência mais rica e complexa.

Nesse processo, é impossível para a indústria da mídia ignorar o poder dos fãs, se por um lado há uma perda de controle sobre o que é produzido, por outro lado há o desenvolvimento de um mercado consumidor bastante significativo. Em virtude disso, como destaca Ortiz (2000, p. 109), o consumo atravessa:

[...] a esfera do lazer e do trabalho, a cultura e a produção, sem opô-los como se fossem pólos antitéticos. Enquanto 'lazer', ele partilha um conjunto de características atribuídas ao 'tempo livre': fruição, deleite, ludismo. Enquanto 'trabalho', reforça-se sua dimensão prioritariamente econômica (em diversos países - Japão, Estados Unidos, Comunidade Europeia - a indústria do entretenimento fatura mais do que as clássicas indústrias de base, grifo do autor).

Assim, cada vez mais os grupos de fãs vêm recebendo destaque, sendo que como:

Os nerds começam a desempenhar papéis principais em filmes, séries de TV e na cultura pop de maneira geral. De The Big Bang Theory, o primeiro sitcom nerd, aos filmes de Kevin Smith, sempre recheados de referências à cultura pop, parece que os nerds começaram a se livrar dos estereótipos que os condenavam em filmes adolescentes da década de 80. (MATTOS, 2011, p. 1).

Se em um primeiro momento os fãs estavam à margem, agora eles possuem também papéis centrais. Com a internet e a possibilidade de organização, surgem cada vez mais eventos especíicos para fãs, dos quais empresas como a Yamato Produções, de São Paulo, já perceberam o potencial, vindo a referida empresa a realizar um dos maiores eventos do gênero na América Latina, o Anime Friends ${ }^{3}$, que atrai caravanas de várias localidades da Brasil e de alguns países da América Latina, com um público em torno de cento e vinte mil pessoas, segundo informações liberadas pela organização do evento. 
No que tange às feiras cosplay, elas são os locais onde se vê mais facilmente a manifestação desse interesse pelas produções midiáticas. São ambientes onde se vive mais intensamente o consumo midiático, não apenas pelas múltiplas possibilidades de adquirir produtos, mas pela possibilidade de interagir com muitos outros fãs e, principalmente, pela possibilidade de dar vida aos seus personagens preferidos, transvestindo-se deles.

Do mesmo modo, são os lugares em que mais facilmente são encontrados os otakus. Eles, assim como outras culturas da mídia, dificilmente podem ser distinguidos em nosso cotidiano. Há casos que você poderia inferir alguma identificação pelo uso de alguma camisa ou acessório de anime, mas, de modo geral, eles passam despercebidos dentre as demais pessoas.

Outra forma pela qual se poderia depreender uma identificação seria prestar atenção aos tópicos sobre os quais conversam: os produtos midiáticos estão no centro de seus assuntos. Comumente, exemplos provenientes dessas produções são utilizados para interpelar o seu cotidiano. Um exemplo disso é o uso da expressão "é maior que One Piece", para dizer que algo é realmente muito extenso, como se não tivesse fim. A obra em questão é uma série de mangá que é publicada desde 1997 pela Weekly Shonen Jump, uma das mais prestigiadas editoras japonesas e que já conta com mais de 850 capítulos.

A Jump publica semanalmente os mangás em formatos de capítulos, sendo periodicamente publicadas compilações desses no formato de volumes. No Brasil, os mangás comercializados pelas editoras consistem em volumes, mas pela atuação de fansubs, a maior parte dos fãs de mangás consegue acompanhar os capítulos em veiculação no Japão. Contudo isso não apresenta implicações no que se refere às vendas de mangás no território brasileiro, muitos fãs, apesar de terem lido a história através dos fansubs, ainda assim investem no produto físico, sendo muito comum ver otakus com sacolas cheias de mangás em feiras cosplay.

Nas feiras, a grande quantidade de títulos disponíveis favorece que sejam encontrados aqueles que os fãs normalmente não encontram nas bancas, principalmente os primeiros volumes de alguns títulos tidos como "raros" e que nesses eventos são vendidos a um custo normal. É comum a venda desses exemplares por preços muito superiores ao valor original por se tratar de títulos mais difíceis de se encontrar. No caso da venda on-line, esta não aparece como alternativa tão interessante para esse tipo de produto, já que muitas vezes o custo do frete de entrega poderá ser igual ou superior ao valor do próprio mangá.

Além dos mangás, nas feiras são compradas réplicas de produtos, como espadas e outros acessórios correlacionados a essas produções. No entanto, a manifestação máxima desse laço com os personagens se dá na prática do cosplay. Essa atividade surgiu nos Estados Unidos na década de 1970, associado a produções como Star Wars e Star Trek. No Brasil, desenvolveu-se após a década de 1990, associada aos animes e impulsionada principalmente pelo sucesso da série Saint Seiya. No entanto, para os otakus, seja nas feiras ou fora delas, com a prática cosplay ou mesmo sem usar um acessório que remeta às produções midiáticas nipônicas, o fator comum aos otakus é a predisposição para a socialização com outras pessoas com interesse nessas produções.

Desse modo, por mais rico que seja o consumo, por maior que seja o número de fontes que possuam, isso não seria o bastante para interpelá-los como otakus. A principal característica do grupo reside nessa necessidade de compartilhar esses seus interesses com os outros fãs das produções, interagir com eles e com aqueles que estejam dispostos a se pôr em relação. Por esse motivo, os otakus costumam ser bastante receptivos, independente do seu grau 
de conhecimento sobre as produções de interesse deles. E esse é um elemento que facilmente eles percebem. Mesmo após ler mangás e ver animes analisando-os para pesquisas, não era incomum me deparar com colocações do tipo:

- "Tô vendo que tu viu o anime, mas não leu o mangá, no mangá é diferente...";

- “Sim, mas não, se tu for ver o capítulo 148, lá ele diz que...";

- "Hahaha... Não te preocupa, vai levar uns dez anos pra tu chegar no nosso nível".

Eles possuem uma percepção diferenciada das obras, o consumo de produtos multimidiáticos associado à constante busca e troca de informações torna-os verdadeiros experts no que se refere a essas produções. Eles não apenas consomem as produções, eles as trazem para suas vidas. Como dito, esse universo é parte de suas vidas, dada através de suas "experiências midiatizadas".

\title{
CONSIDERAÇÕES FINAIS
}

\author{
"Faça elevar o cosmo no seu coração \\ Todo o mal combater \\ Despertar o poder \\ Sua constelação sempre irá te proteger \\ Supera a dor e dá forças pra lutar..." \\ (Pegasus Fantasy - Angra)
}

Esse trecho refere-se à tradução da canção Pegasus Fantasy, apresentada no início deste estudo e que consiste na versão brasileira da abertura do anime Saint Seiya. Ele serve principalmente para relembrar o ponto chave deste trabalho, a forma como os produtos midiáticos e os consumidores se relacionam, dando origem a um grupo baseado em uma cultura da mídia. Podemos considerá-lo então como sendo o hino nacional dos otakus. Afinal, dificilmente se encontrará um que não reconheça essa música ou que a não tenha escutado em alguma feira cosplay.

Cavaleiros do Zodíaco, juntamente com a implementação da internet no Brasil e sua subsequente popularização associada à melhoria nas tecnologias de comunicação, proporcionaram um novo cenário para os consumidores. Cenário esse caracterizado pela independência das mídias tradicionais e pelo crescimento da atividade dos fansubs. Concomitantemente, testemunhamos diversas mudanças na própria organização da sociedade brasileira, perceptíveis também como a própria mudança nas grades de programação de nossas emissoras de televisão.

Em meio a tudo isso, presenciamos um fenômeno inusitado: a popularização de produtos midiáticos nipônicos, processo que se deu ao ponto de não apenas competirem com consagradas produções ocidentais, mas que, em seu consumo on-line, supera-as com uma grande vantagem. Encontramos assim profundas mudanças na cadeia de produção, mudanças que tornaram os consumidores menos passivos e obrigaram a indústria da mídia a se adequar a sua vontade, resultado do desenvolvimento de uma economia afetiva.

Frente a isso, contrapomos as teorias de Kellner (2001) e Jenkins (2008), respectivamente, à Teoria da Cultura da Mídia e à da Cultura da Convergência. Nisso, situamos um ponto entre as duas, algo que enquadramos dentro da dualidade da estrutura, conceito de Giddens (1978), de tal modo que se tornou perceptível a ação de duas forças em constante negociação, o agente e a estrutura; o fã e a indústria da mídia. Certamente as condições neste jogo não são iguais, no entanto os avanços tecnológicos na área da comunicação têm 
cada vez mais auxiliado a diminuir essa disparidade, sendo que em determinados casos podemos considerar até mesmo um possível equilíbrio entre elas.

No cerne desse processo, tornou-se evidente que cada vez mais há uma especialização das produções midiáticas para se adaptar à nova realidade. A indústria japonesa, podendo ser considerada uma pioneira neste processo, sendo o seu principal caso a obra Saint Seiya, que abriu as portas de inúmeros países para a circulação dos animes japoneses. No entanto, o processo de especialização das produções midiáticas se torna mais perceptível ao ilustrar o processo de serialização dos mangás, uma competição semanal para se manter em veiculação que forçou os mangakás a explorarem de forma bastante eficientes recursos que promoveriam a aceitação por parte do público.

Neste processo de especialização dos produtos midiáticos aparece com fundamental importância o conceito de identificação. Ao nos identificarmos com situações vivenciadas pelos personagens, começamos a nutrir um certo grau de simpatia por ele. Essa relação, trabalhada através da continuidade, acaba desenvolvendo um vínculo extremamente forte entre produções e consumidores, fazendo com que desenvolvamos um elo sentimental com as produções. E, com as possibilidades decorrentes da circulação de produtos multimidiáticos, temos experiências de consumo mais ricas. Além disso, tal fenômeno permite uma imersão ainda maior na obra, na qual o fã se destaca como um verdadeiro expert pela busca constante de atualizações e trocas frequentes de informações com os demais fãs das produções.

Dentro dessa busca de experiências por parte dos fãs, novas possibilidades se originam. Eles exploram as produções de forma que os produtores nem poderiam imaginar. As produções passam a fazer parte de seu cotidiano, seja pelo uso de camisas ou acessórios; seja como referências dentro de suas falas; seja nas nuances de seus relacionamentos com os demais fãs. Não apenas isso, mas popularizam-se os lugares que lhes são próprios, as feiras cosplay, eventos nos quais encontramos a manifestação máxima dessa cultura.

Nas feiras eles interagem, trocam informações, adquirem produtos e, principalmente, encarnam os personagens através de suas fantasias. Nesse universo de consumo a grande premissa é o divertir-se, mas não apenas com as produções; a diversão está associada ao compartilhar, ao dividir com o grupo. Vislumbramos nisso a base que sustenta a teoria de Jenkins, o desenvolvimento de uma cultura baseada na participação, e de uma economia afetiva na qual o consumo midiático é a base para o colocar-se em relação. Nesse contexto, as experiências midiatizadas são enriquecidas por esse compartilhamento ao mesmo tempo em que novas experiências são criadas, e eles se percebem como iguais, como um grupo.

\section{NOTAS}

${ }^{1}$ Resolução Full HD diz respeito ao padrão de formato de imagem com 1080p, imagens de alta definição.

${ }^{2}$ Name - termo usado para se referir aos manuscritos dos mangás que são submetidos a avaliação do editor.

${ }^{3}$ Após 14 anos o Anime Friends juntamente com o Ressaca Friends, eventos organizados pela Yamato Produções foram vendidos para o Grupo Rogrene, em setembro de 2017. 


\section{REFERÊNCIAS}

ANDERSON, Chris. A Causa Longa: do mercado de massa para o mercado de nicho. 1 Ed. Rio de Janeiro: Elsevier: B2W, 2005.

ALVES, Julia Falivene. A invasão cultural norte-americana. 26 Ed. São Paulo: Moderna. 1996.

AUMONT, Jacques, MARIE, Michael. Dicionário teórico e crítico de cinema. São Paulo: Papirus, 2003.

BARRAL, Étienne. Otaku: Os filhos do virtual. São Paulo: SENAC, 2000.

CAMPOS, Vanessa P. M. O que é feminina? Disponível em: <http://intercom. org.br/papers/nacionais/2008/resumos/R3-2118-1.pdf.>. Acesso em: 07 jul. 2016.

CHAUI, Marilena. Simulacro e Poder. São Paulo: Editora Fundação Perseu Abramo, 2006.

COELHO JUNIOR, Leconte de L.e SILVA, Sara S. Cosplayers como fenômeno psicossocial. Revista Brasileira de Crescimento e Desenvolvimento Humano. 2007. Disponível em: <www.journals.usp.br/jhgd/article/download/19815/21886>. Acesso em: 10 jul. 2016.

DEBORD, Guy. A Sociedade do espetáculo. eBooksBrasil.com, 2003. Disponível em: $<$ http://www.ebooksbrasil.com/eLibris/socespetaculo.html $>$. Acesso em: 03 ago. 2011.

DUMONT, Louis. "Noção de estrutura" e "A oposição fundamental". Homo Hierarchicus. São Paulo: Edusp, 1997.

ECO, Humberto. Apocalípticos e Integrados. São Paulo. Editora Perspectiva S.A., 1993.

GARBIN, Elisabete M. Culturas juvenis urbanas. II Simpósio Internacional. V Fórum Nacional de Educação, 2003. Disponível em: $<$ http://forum.ulbratorres. com.br/2008/mesa_texto/MESA\%2014B\%20-\%20GARBIN.pdf >. Acesso em: 12 jul. 2015.

GIDDENS, A. Novas regras do método sociológico: uma crítica positiva das sociologias compreensivas. Rio de Janeiro: Zahar, 1978.

GIDDENS, Anthony. A Constituição da Sociedade. São Paulo: Martins Fontes, 2009.

GEERTZ, Clifford, 1926-A interpretação das culturas/Clifford Geertz. 1. ed., IS.reimpr. - Rio de Janeiro: LTC, 2008.

ISSA, Victor Eiji. Otaku: um sujeito entre dois mundos. Refletindo sobre o diálogo existente entre ficção e realidade. Tese de Doutorado. Programa de Pós-Graduação em Antropologia Social / USP. São Paulo, 2015. Disponível em: <http://www.teses.usp.br/teses/disponiveis/8/8134/tde-01062015-154037/ pt-br.php>. Acesso em: 7 jul. 2016

JBC ON LINE. Disponível em: <http://www.editorajbc.com.br/websites>. Acesso em: 07 abr. 2015.

JENKINS, Henry. Cultura da convergência. São Paulo: Aleph, 2008.

KATEKAWA, Henrique Eidin. Fenômeno otaku: de problema social à solução política. Tese de Doutorado. Programa de Pós-Graduação em Língua, Literatura e Cultura Japonesa / USP. São Paulo, 2016. Disponível em: <Fenômeno otaku: de problema social à solução política>.

KELlNER, D. A Cultura da Mídia - Estudos Culturais: Identidade e Política entre o Moderno e o Pós-Moderno. São Paulo: EDUSP, 2001.

LEACH, E. "Introdução" e "Conclusão". Sistemas Políticos da Alta Birmânia. São Paulo: Edusp, 1996. 
LIPOVETSKY, Gilles. O Império do Efêmero: A moda e seu destino nas Sociedades Modernas. São Paulo: Companhia das Letras, 1989.

LOUREIRO, André L. C. Otakus: Construção e representação de si entre aficionados por cultura pop nipônica. Tese de Doutorado. Programa de Pós-Graduação em Antropologia Social/ Museu Nacional/ UFRJ. Rio de Janeiro, março de 2009.

LUYTEN, Sonia B. Mangá: o poder dos quadrinhos japoneses. 3 Ed. São Paulo: Hedra, 2012.

MACHADO, Carlos A. Animencontros: hibridismo cultural midiático como consequência do relacionamento na forma de novos costumes juvenis. Disponível em:<www.intercom.org.br/papers/nacionais/2009/resumos/R4-3480-1. pdf $>$. Acesso em: 18 set. 2016.

McCLOUD, Scott. Desenhando Quadrinhos. São Paulo: M. Books do Brasil, 2008.

MCCOMBS, Maxwell. A Teoria da Agenda: a mídia e a opinião pública/ Maxwell McCombs; Tradução de Jaques A. Wainberg. - Petrópolis, RJ: Vozes, 2009.

MATTOS, Patrícia. O nerd virou cool: identidade, consumo midiático e capital simbólico em uma cultura juvenil em ascensão. In: Intercom - Sociedade Brasileira de Estudos Interdisciplinares da Comunicação XVI Congresso de Ciências da Comunicação na Região Sudeste - São Paulo - SP - 12 a 14 de maio de 2011. MORELLI, André. Super-heróis nos desenhos animados. São Paulo: Europa, 2010.

NAGAMI, Iris. Antropologia da performance: A experiência do cosplay e as ações perfomáticas. VIII Seminário de Pesquisa em Ciências Humanas. 2010. Disponível em: $<\mathrm{http}: / /$ www.uel.br/eventos/sepech/sumarios/temas/antropologia_da_performance_a_experiencia_do_cosplay_e_as_acoes_performaticas. pdf $>$. Acesso em: 20 ago. 2016.

NORONHA, Fernanda Silva. Animês e mangás: o mito vivo e vivido no imaginário infantil. Tese de Doutorado. Programa de Pós-Geaduação em Educação / USP. São Paulo, 2013. Disponível em: <http://www.teses.usp.br/teses/disponiveis/48/48134/tde-17122013-152946/pt-br.php>. Acesso em: 12 set. 2016.

ORTIZ, Renato. Mundialização e cultura. São Paulo: brasiliense, 2006.

ORTIZ, Renato. O próximo e o distante: Japão e modernidade - mundo. São Paulo: Brasiliense, 2000.

PERES, Leandro Ayres. Cultura, mídia e identidade: os animes japoneses no Brasil. Monografia (Graduação em Comunicação Social - Habilitação em Publicidade e Propaganda) Departamento de Ciências da Comunicação,Universidade Federal de Santa Maria, Santa Maria, 2008.

REDE MANCHETE DE TELEVISÃO - Portal da Manchete. Disponível em: $<w w w$. redemanchete.net $>$. Acesso em: 18 jul. 2017.

SANTAELLA, Lucia. Culturas e artes do pós-humano: Da cultura das mídias a cibercultura. São Paulo: Paulus, 2003.

SATO, Cristiane A. Japop - o poder da cultura pop japonesa. São Paulo: NSP-Hakkosha, 2007.

Schüler COSTA, Vlad. Geração Sentimental: A Construção Social do Otaku. In: I Seminário Nacional do Programa de Pós-Graduação em Ciências Sociais - PGCS - UFES, em 01/06/2011. Disponível em: <http://periodicos.ufes.br/ SNPGCS/article/view/1568>. Acesso em: 01 jun. 2014.

SILVA, Erotilde Honório, ANDRADE Roberta Manuela Barros. Sociabilidades midiáticas: flexibilidade, mutação e pluralidade. Comunicação, mídia e consumo. v. 3, n. 6. São Paulo, Março/2006. 
SILVA, Tomaz Tadeu da; HALL, Stuart; WOODWARD, Kathryn. Identidade e diferença: a perspectiva dos estudos culturais. 4 Ed. Petrópolis: Vozes, 2005.

SILVEIRA, Jacira C. da. Infância na Mídia - sujeito, discursos e poderes. Disponível em: $<$ http://www.anped.org.br/reuniões/23/textos1616t.PDF.>. Acesso em: 07 jul. 2009.

SILVERSTONE, Roger. Por que estudar a midia? São Paulo: Loyola, 2002.

SIMMEL, Georg. Questões fundamentais da Sociologia. Rio de Janeiro: Zahar, 2006.

SIMMEL, Georg. Sociologia. São Paulo: Ática, 1983.

SODRÉ, Muniz. Antropológica do espelho: por uma teoria da comunicação linear e em rede. RJ, Vozes, 2002.

TOCCI, Jason. Geek Cultures: Media and Identity in the Digital Age (2009). Publicly Accessible Penn Dissertations. Paper 953.

VICENTE, Patrícia M. B. O desenho Animado Como Sistema Modelizante. INTERCOM - Sociedade Brasileira de Estudos Interdisciplinares da Comunicação. XXVI Congresso Brasileiro de Ciências da Comunicação - BH/MG - 2 a 6 Setembro de 2003. Disponível em: <www.intercom.org.br/papers/ nacionais/2003/www/pdf/2003_NP15_vicente.pdf\$. Acessado em: 10 jul. 2016.

VIEIRA, Eloy Santos, ROCHA, Irla Suellen da Costa, FRANÇA, Lilian Cristina Monteiro. A aproximação entre indústrias midiáticas e os fãs: o caso do DramaFever no Brasil. Intercom - Sociedade Brasileira de Estudos Interdisciplinares da Comunicação XXXVIII Congresso Brasileiro de Ciências da Comunicação - Rio de Janeiro, RJ - 4 a 7/9/2015. Disponível em: <http:// portalintercom.org.br/anais/nacional2015/resumos/R10-1893-1.pdf $>$. Acesso em: 17 mai. 2016. 